\title{
T-tube Enterostomy Versus Foley Catheter Enterostomy: Techniques for Different Situations: Reply
}

\author{
Anders Tøttrup
}

Published online: 12 February 2011

(c) Société Internationale de Chirurgie 2011

Dr. Sanjah Marwah is to be thanked for his comments [1] on my recent article [2] on the use of a Foley catheter enterostomy for postoperative bowel perforation. Dr. Marwah describes some of the difficulties encountered when using a balloon catheter to seal a bowel perforation, and some of these difficulties are beautifully illustrated by photos. For the conditions shown by Dr. Marwah, I fully agree that a T-tube enterostomy is a far better option than a Foley catheter enterostomy. When considering a Foley catheter enterostomy for postoperative bowel perforation, it is imperative to keep in mind the benefits and limitations of this technique as outlined in my article [2]. First, the defect has to be small and the surrounding bowel wall should be viable and solid. Second, it is imperative that the defect can reach the inside of the abdominal wall at a location where a Foley catheter can be inserted through a small stab wound without any tension on the bowel. I believe that these conditions were not met in any of the examples presented by Dr. Marwah. To be more specific, if the perforation cannot reach the inside of the abdominal wall, there is no point in increasing the volume of the Foley catheter balloon. This will, as pointed out by Dr. Marwah, only lead to creating a larger defect in the bowel. For duodenal leaks, I find the Foley catheter technique of no use, as these defects will never reach the abdominal wall without tension. By following strictly the indications and directions for placement of a Foley catheter enterostomy, we have seen no limitations in the oral intake as soon as bowel paralysis has settled.

The advantages of the Foley catheter technique are that it provides immediate and full source control and that early enteral feeing is possible. In addition, later operation for closure of an intestinal fistula is rarely required because of spontaneous closure after removal of the catheter.

I hope that this technique will not be discredited because of incorrect use.

\section{References}

1. Marwah S (2011) Foley catheter enterostomy for postoperative bowel perforation: an effective source control. World J Surg 35. doi: 10.1007/s00268-010-0916-3

2. Tøttrup A (2010) Foley catheter enterostomy for postoperative bowel perforation: an effective source control. World J Surg 34(11): 2752-2754

\footnotetext{
A. Tøttrup $(\bowtie)$

Department of Surgery P, Aarhus University Hospital,

Tage-Hansensgade, 8000 Aarhus, Denmark

e-mail: anders_tottrup@hotmail.com
} 